\section{CARDIAC MASSAGE}

BY

\section{JOHN C. NICHOLSON, F.R.C.S. Major, R.A.M.C.}

The subject of restarting the heart's action by cardiac massage is of great interest and importance, and is one which is constantly recurring in medical literature. Hamilton Bailey's recent paper (Journal, July 19, 1941, p. 84) and the ensuing correspondence prompt me to record a series of 7 cases, in 6 of which I have had to resort to this procedure and which bring out certain points of interest and lead to certain definite conclusions. I cannot lay claim to anything like Mr. Bailey's extensive experience of 40 cases in over twenty years' surgical practice (Journal, August 16, 1941, p. 243), but these seven cases have occurred out of 3,500 operations of various kinds in the last twelve years, and approximately correspond to my number of "deaths on the table."

\section{Case Reports}

Case 1.-Spinster aged about 50, suffering from bilateral renal tuberculosis with secondary involvement of the bladder, giving rise to severe and continuous pain. Operation on October 31, 1939: presacral neurectomy under gas-and-oxygen and ether. While the sympathetic plexus was being dissected off the bifurcation of the aorta, the pulsations suddenly became slower and stopped. Almost at once a hand was pushed up under the diaphragm; the heart was felt to be motionless and dilated. After a few firm compressions against the chest wall, through the diaphragm, the heart started beating again-slowly at first (about 40 a minute), then gradually regaining its normal rhythm. (In this respect this case differed from the others I have seen; for, in these, when the heart started to beat again it did so at a greatly increased rate, generally from 120 to 180 beats a minute.) The heart had been stopped probably not more than one minute before it was restarted, and the operation was then rapidly completed. The patient made an uneventful recovery from the operation, which was successful in relieving her bladder pain during the remainder of the period she was under observation. At no time were there any signs of the effects of the temporary cessation of circulation on the nervous system.

Case 2.-Man aged 45 ; laparotomy for perforated duodenal ulcer on April 25, 1938, under spinal (percaine) and light gasand-oxygen anaesthesia. After closing the peritoneum, and while suturing the muscle layers, the heart stopped beating and was inaudible on the stethoscope. The stitches were hastily cut and the abdomen reopened, and cardiac massage was started by compression of the heart against the chest wall, through the diaphragm. No response being obtained, an opening was made in the diaphragm behind the xiphoid process by rapid blunt dissection, and the thumb of the right hand was thrust into the pericardium in front of the heart itself. The heart was then rhythmically compressed between the thumb, in front, and the fingers, acting at the back through the diaphragm. The heart started beating about three and a half minutes after it had stopped, and took on a rapid rate, about 120 beats a minute, which was maintained for some hours after the operation. The man recovered after a stormy convalescence, complicated by pneumonia, and is alive and well now, so far as I know. $\mathrm{He}$ recovered consciousness about two hours after the operation, and at no time showed any signs of neurological disturbance.

Case 3.-Married woman aged about 50, with a previous history of addiction to alcohol and drugs. Operation on August 9, 1939, for severely comminuted fracture of the patella. Anaesthesia was induced with sodium pentothal and followed by gas-and-oxygen and ether. (Unknown to me she had had a preliminary injection of $1 / 4$ grain of morphine.) The right patella was removed through a medial incision. While the final skin sutures were being put in respiration suddenly ceased and she rapidly became pulseless. After a minute or so I proceeded to open the abdomen by a midline incision extending from the xiphoid process downwards, and began cardiac massage, at first by compression of the heart through the diaphragm, and shortly afterwards by resorting to the method described in Case 2. The heart started to beat again seven and a half minutes after it was first discovered to have stopped; it was soon beating at about 140 beats a minute, and within two hours had practically recovered its normal rate. About ten minutes after the heart had restarted respiration was resumed and artificial respiration was discontinued. After the operation the patient did not really recover consciousness. On the fifteenth day following operation she died from bronchopneumonia, which became apparent two days before death. During this period she presented a most interesting clinical picture : for the most part she was comatose, but at times was very restless, muttering odd words and picking the bedclothes. Her reflexes were normal and her general condition quite good until the last two days. She swallowed soft food reflexly when it was put into her mouth, and cried out when painful stimuli, such as a pin-prick, were applied; defaecation and micturition were carried out reflexly. Her condition closely resembled that of the "thalamus animal" in which the cerebral cortex has been removed, the lower parts of the brain and the spinal cord apparently functioning satisfactorily, and we suspected that a massive thrombosis of the cerebral vessels had occurred. After death a necropsy, carried out by Sir Bernard Spilsbury, revealed that bronchopneumonia was the immediate cause of death; the heart was normal, and showed no signs of injury as a result of cardiac massage, and the small opening in the pericardium, beneath the xiphoid process, was closed by recently formed fibrous tissue. The brain appeared normal, and no macroscopic or microscopical changes were apparent ; there was no evidence of thrombosis or embolism in any of the cerebral vessels.

Case 4.-Man aged 20, suffering from pituitary tumour. Operation on November 17, 1938. After induotion of anaesthesia with gas-and-oxygen, novocain was injected into the scalp. Before the incision was started he stopped breathing, and shortly afterwards the heart ceased beating. There was some delay before the abdomen was opened and cardiac massage was begun - at first through the diaphragm and later by inserting the thumb into the pericardium. The heart started to beat again fificen minutes after it had stopped; the pulse rate rose to 180 beats a minute, gradually falling to the neighbourhood of 100 ; and respiration recommenced about twenty minutes after the heart restarted. The patient never recovered consciousness, and remained in a comatose condition with periods of restlessness for twelve hours after the operation; his pulse then started to rise, and he died. Necropsy showed no changes in the brain other than those associated with the presence of the pituitary tumour; the heart was rather fatty and soft, but had been undamaged by the cardiac massage.

Case 5.-Man aged about 45 . He had sustained a severe head injury, and developed left-sided Jacksonian fits due to a right-sided subdural haemorrhage associated with some degree of cerebral laceration. Operation on December 10, 1938, about twelve hours after the accident. A rapid right subtemporal decompression was attempted, no anaesthetic being used. His heart failed before the skull was opened; this was rapidly accomplished and decompression carried out. The abdomen was opened within a few minutes, and cardiac massage was started by the direct method. No response whatever was obtained. Necropsy showed no damage to the heart by massage.

Case 6.-Man aged 70, suffering from acute intestinal obstruction due to a large strangulated hernia. Operation on December 6, 1938, under spinal (percaine) anaesthesia. The hernial sac was opened and the bowel was found to be obstructed but not gangrenous; a large quantity of foul-smelling exudate was present in the sac. As the bowel was being reduced into the abdomen he lost consciousness and started to vomit, and the heart failed. The abdomen was opened, and cardiac massage was carried out without any response. Necropsy showed that intestinal contents had been aspirated into the larynx but had not reached the trachea or bronchi. Presumably the heart had stopped owing to a reflex acting through the recurrent laryngeal nerves. 
Case 7.--Young man, operated upon in 1930 by another surgeon, tonsillectomy being carried out. While the second tonsil was being pulled forward in dissection the man was obviously very lightly under the anaesthetic. $\mathrm{He}$ suddenly collapsed, and the heart was found to have stopped. The abdomen was opened and cardiac massage performed by compressing the heart against the ribs through the diaphragm only. No response was obtained. I regard the cause of this man's sudden cardiac failure as again being due to recurrent laryngeal reflex while insufficiently anaesthetized, and $I$ have seen a similar sudden cardiac failure occur reflexly when the mesentery was pulled upon in a patient not sufficiently under. The failure of cardiac massage was presumably partly due to the delay in initiating it and partly because it was inefficiently carried out.

\section{Commentary}

It seems that sudden heart failure during operation may be attributable to one of two causes. In the first group the heart has failed as a terminal event in a mortal illness, such as late intestinal obstruction, general peritonitis, and any operation in the emaciated and aged. Cases 5 and 6 belong to this group, and in my view nothing one can do would revive the heart. In the other class of case the heart has presumably failed either owing to reflex inhibition or possibly as a result of the toxic action of the anaesthetic agent, and in these cases cardiac massage is generally successful in initiating the heart-beat, and should be resorted to at once.

The ultimate benefit depends entirely on the interval of time between the heart's cessation and its restarting. It appears that the effects of temporary circulatory failure are due to some damage caused by the resulting anoxaemia on the most highly specialized cells in the brain-i.e., in the cerebral hemispheres. What this time interval is has been disputed. I have seen it put as high as ten minutes, but it would seem to be much shorter.

In none of my cases that have come to necropsy has there been any demonstrable change in the brain, either macroscopically or histologically; and $\mathrm{Sir}$ Bernard Spilsbury, who has done most of my necropsies, informs me that his experience has been the same in other cases. $\mathrm{He}$ also told me that he had on several occasions seen very severe damage to the heart and diaphragm caused by injudicious attempts at cardiac massage.

Below is a summary of the first four of these cases and of the one published in Mr. Bailey's paper:

\begin{tabular}{|c|c|c|c|}
\hline Operation & $\begin{array}{l}\text { Time before } \\
\text { Heart starts } \\
\text { to Beat }\end{array}$ & $\begin{array}{l}\text { Effect on Nervous } \\
\text { System }\end{array}$ & Result \\
\hline 1. Presacral & Under $1 \mathrm{~min}$. & Nil & Recovered \\
\hline 2. Perforated & $3 \frac{1}{2}$ mins. & Not apprcciable & , \\
\hline $\begin{array}{l}\text { 3. Epididymectomy } \\
\text { (Mr. Bailey's case) }\end{array}$ & $5 \frac{1}{2} \quad "$ & $\begin{array}{l}\text { Marked signs of damage } \\
\text { to brain. Recovered } \\
\text { consciousness in a few }\end{array}$ & $\begin{array}{l}\text { Recovered } \\
\text { (ultimately) }\end{array}$ \\
\hline 4. Removal of patella & $7 \frac{1}{2} \quad$, & $\begin{array}{l}\text { hours } \\
\text { Very marked; lived } 14 \\
\text { days in a " decere- } \\
\text { brate state" }\end{array}$ & $\begin{array}{l}\text { Died on 15th } \\
\text { day without } \\
\text { recovering } \\
\text { consciousness }\end{array}$ \\
\hline 5. Cerebral tumour & 15 & $\begin{array}{l}\text { Profound; never re- } \\
\text { covered consciousness }\end{array}$ & $\begin{array}{l}\text { Died after } 12 \\
\text { hours }\end{array}$ \\
\hline
\end{tabular}

The vital interval during which cardiac massage may be of avail is therefore between three and six minutes; after this it would seem to be useless. For this reason I think it cannot be too strongly urged that no time should be wasted in injecting adrenaline or coramine into the heart muscle, which, in any case, usually fails to get there; nor should time be wasted on more than the bare essential instruments required-which do not consist of more than a knife in the first instance, available during any operation. Nor is it necessary to appoint timekeepers, as Mr. Bailey suggests ; for it is better to have a live patient, even if he has peritonitis or an infected abdominal wound, than a dead one after a well planned and executed operation.

It may take some courage to decide on opening the abdomen to massage the heart if one feels not quite sure ; but during those few moments of procrastination the patient's chances of recovery are ebbing away at a speed only exceeded when he has an uncontrolled haemorrhage from a large artery. The mind has to be made up at once if any good is to be done.

\section{The Operative Procedure}

The operation I have carried out is simple, and I think it is to be preferred to that described by Mr. Bailey, who advocates dividing the attachment of the diaphragm to the ribs, and inserting the hand into the pericardium and compressing the whole heart in the hand. This procedure is bound to do much more damage, and takes longer to perform and to repair than the method I use. A rapid incision is made in the midline from the tip of the xiphoid process downwards for three to four inches. Such an incision generally exposes the front of the liver only. It should not be made too long, or the stomach and bowel may be extruded, thereby wasting time; but the incision must be large enough to admit the whole hand. Usually the peritoneum can be exposed in one cut. No haemorrhage to speak of occurs, as the circulation has ceased, and it is unnecessary to waste time picking up vessels. This can be done later if and when the heart has been restarted. The right hand is pushed up between the diaphragm and the liver, and the heart compressed against the ribs through the diaphragm. This should not be persisted in for more than a few seconds, as it is nearly always ineffective if the heart has really stopped. This method is inefficient because only the tip of the heart is compressed, and the organ tends to slip away upwards when compressed against the chest wall. The following procedure should be adopted at once: an opening is made with a knife or a pair of scissors just behind the xiphoid process, between the attachments of the two sides of the diaphragm. There is a soft avascular spot here, and no damage is likely to be done by this approach (which, incidentally, is an excellent method of effecting drainage from the pericardium also). The thumb of the right hand is thrust through this opening, and is now in the pericardium anterior to the heart. The heart is then compressed between the thumb, which acts by fixing the heart and preventing it slipping, and the fingers outside the diaphragm. The pressure should be rhythmical, at about 80 compressions a minute ; if kept up for any length of time it is very tiring to the hand. When the heart starts to beat, it should be assisted for a few minutes until the beat is well established. What generally happens is that when the heart is grasped it is motionless, flabby, and dilated. After rhythmical compression for a varying interval, the ventricular muscle can be felt to start fibrillating. Shortly after this the heart as a whole begins to beat feebly. The heartbeat soon gathers strength, and proceeds at a considerable rate, until it gradually settles down into its normal rhythm. When the beat is well established the abdominal wall can be dealt with, and closed at leisure. It is quite unnecessary to suture the small hole in the pericardium. Artificial respiration should be proceeded with throughout the whole operation, and continued until natural respiration has been re-established.

I would emphasize again the extreme urgency of this condition, which may arise in any operation, however trivial. The point is that one must make up one's mind at once, and act with the utmost speed. Only if this is done is any good likely to ensue. 